NBER WORKING PAPER SERIES

\title{
RELATIVE PRICE VARIABILITY AND INFLATION: EVIDENCE FROM US CITIES
}

\author{
Guy Debelle
}

Owen Lamont

Working Paper 5627

\section{NATIONAL BUREAU OF ECONOMIC RESEARCH 1050 Massachusetts Avenue \\ Cambridge, MA 02138 \\ June 1996}

We thank Joe Beaulieu, Roland Benabou, Fischer Black, Olivier Blanchard, John Cochrane, Stanley Fischer, Michael Gibson, Julio Rotemberg, two anonymous referees, and participants at the February 1995 NBER Economic Fluctuations conference (especially Larry Ball and Mariano Tommasi) for helpful comments. Lamont thanks the National Science Foundation for financial support. This paper is part of NBER's research program in Monetary Economics. Any opinions expressed are those of the authors and not those of the International Monetary Fund or the National Bureau of Economic Research.

(C) 1996 by Guy Debelle and Owen Lamont. All rights reserved. Short sections of text, not to exceed two paragraphs, may be quoted without explicit permission provided that full credit, including $(\mathcal{C}$ notice, is given to the source. 


\title{
RELATIVE PRICE VARIABILITY AND INFLATION: EVIDENCE FROM \\ US CITIES
}

\begin{abstract}
We test whether the time-series positive correlation of inflation and intermarket relative price variability is also present in a cross-section of US cities. We find this correlation to be a robust empirical regularity: cities which have higher than average inflation also have higher than average relative price dispersion, ceteris paribus. This result holds for different periods of time, different classes of goods, and across different time horizons. Our results suggest that at least part of the relationship between inflation and relative price variability cannot be explained by monetary factors.
\end{abstract}

Guy Debelle

Research Department

International Monetary Fund

Room IS12-404

Washington, DC 20431
Owen Lamont

Graduate School of Business University of Chicago 1101 East 58th Street Chicago, IL 60637 and NBER 


\section{Introduction}

Time series evidence suggests that inflation and relative price changes are strongly positively correlated. A variety of theories can explain this correlation, but the existing evidence is inconclusive about the causal mechanism that generates the observed facts. In this paper, we present new evidence on the relationship between inflation and relative price variability by examining a cross-section of US cities in the post-war period. The value of this approach is that it controls for nation-wide shocks, including changes in monetary policy and oil prices. We find that inflation and relative price variability are strongly positively correlated at the city level, suggesting that aggregate shocks (such as monetary factors) are not entirely responsible for the correlation.

The movement of individual prices relative to the aggregate price level has been investigated at least since Mills' classic description of the US price system (1927). Previous empirical work has examined time series data on the relationship between relative price variability and inflation in different countries and in different inflationary environments. This work has defined relative price variability as the standard deviation (or variance) of the rates of inflation of various categories of goods and services around the average consumer price inflation rate, that is, inter-market price variability. Vining and Elwertowski (1976), Parks (1978), and subsequent researchers found evidence that inflation and relative price variability are positively correlated over time. A separate, dissenting set of researchers have variously concluded that there is no statistical relationship between inflation and relative price variability, or that the correlation is caused entirely by energy and food prices, or that the question or the statistical tests used are ill-defined.

Figure 1 illustrates the standard result in the literature. It updates Figure 1 in Fischer (1981), 
plotting the US inflation rate (as measured by the Consumer Price Index) against the standard deviation of the inflation rates of 14 components, data which we use in the empirical analysis. ${ }^{1} \mathrm{~A}$ brief glance at Figure 1 conveys some of the main elements of the debate about inflation and relative price variability (hereafter RPV) in US postwar history. As noted by Fischer, both series have peaks around 1974 and 1979 , when the price of oil rose due to supply disruptions. Note also that RPV rises in 1986, while oil prices and inflation fell.

The problem with Figure 1 is that it is consistent with many different causal mechanisms. Some price setting theories imply that RPV causes inflation; others imply that inflation causes RPV. A third alternative is that the classical dichotomy holds: in a world where money is neutral and prices are fully flexible, nominal inflation is irrelevant to RPV. The classical dichotomy would be fully consistent with the evidence in Figure 1, for example, if the Fed consistently increased the money supply in response to real shocks to RPV.

In this paper, using data on annual consumer price inflation, we find that across US cities the positive correlation between inflation and relative price variability is a robust empirical regularity. US cities which have inflation above the national average in a given year also have a higher degree of relative price variability. This relationship holds for different categories of goods and services, for different subperiods, and controlling for fixed city and year effects. ${ }^{2}$

Section II briefly discusses the theoretical underpinnings for the relationship between

${ }^{1}$ Fischer uses the consumption deflator; in this paper we study the CPI because it is available by city. The main difference between these two sources is that using the consumption deflator, RPV has a much larger peak in 1986 when oil prices fell.

${ }^{2}$ Related evidence from US cities, using a different data source than ours, is presented in Parsley (1995). He reaches conclusions similar to ours. 
RPV - Page 3

inflation and relative price variability, and outlines the empirical controversy. Section III explains our data and our approach. Section IV shows our results. We sketch out extensions in Section V. Section VI presents our conclusions.

\section{Theories and Existing Evidence}

Fischer (1981) and Weiss (1993) provide useful summaries of the theoretical and empirical links between inflation and relative price variability. One theory is that unanticipated inflation creates "misperceptions" of absolute and relative price changes, which leads to RPV (Lucas (1973) and Barro (1976)). Menu costs may generate a positive relationship between the level of inflation and RPV (Sheshinski and Weiss (1977)). Search models also imply a link between inflation and RPV (Benabou (1988)).

Ball and Mankiw (1994) present a menu-cost model where shocks that raise firms' desired prices trigger larger price responses than shocks that lower desired prices. In this world, above average inflation is in a sense caused by high RPV, and prices are sticky downward. To preview our results, we find evidence consistent with this model, since we find that above average inflation is related to above average RPV but that below average inflation is not. The models presented in Ball and Mankiw $(1994,1995)$ seem particularly relevant to city data since it is chiefly real shocks, not nominal shocks, that vary at the city level compared to the national level.

The empirical literature on relative price variability and inflation dates back to Mills (1927) who provided a comprehensive survey of the US price system by examining the levels of, and movements in wholesale price indexes and their components over the period 1890-1926. As part of his survey, Mills examined the relationship between shifts in the price level and changes in the degree of dispersion (defined as the standard deviation of relative prices). 
RPV - Page 4

Mills' work was updated and refined by Vining and Elwertowski (1976) who used the wholesale price index at the 8 digit level (about 100 items) over the period 1947 to 1974 . They confirmed Mills' finding that relative price variability was positively correlated with inflation. Using the standard deviation of changes in the various components of the wholesale price index to measure variability, their results produced a positive coefficient of 0.43 in a regression of relative price variability on inflation. They also found that the distribution of price changes exhibited a positive skew which was increasing in the level of inflation. That is, most price changes were below the average rate of inflation but a few prices changed by an amount significantly above average.

As a brief check, we reproduced the analysis of Vining and Elwertowski, using the aggregate data from Figure 1. The data run from 1954 to 1986 (33 annual observations) and use inflation rates from 14 different categories of goods to calculate RPV. A regression of the standard deviation of the inflation rates of the components against the total CPI inflation rate yields a significant, positive coefficient of 0.32 .

Similar findings of a positive correlation between inflation and relative price variability were found by Parks (1978) for the Netherlands (1921-1963) and the US (1930-1975), by Graham (1930) for the German hyperinflation, by Glejser (1965) for a cross-section of European countries, and by Fischer (1981) and (1982) for the US (1931-1980) and Germany (1967-1980). Thus the correlation between relative price variability and inflation has been found across different countries, in times of hyperinflation, stable low inflation, uncertain inflation and deflation.

Some work has attempted to determine whether the relationship is stronger between inflation and RPV using the level of inflation or unanticipated changes in inflation. Parks (1978) found that 
for the US, it was driven by the relationship between unanticipated inflation rather than the level of inflation. Fischer (1981) regressed relative price variability on inflation, changes in inflation, and expected and unexpected inflation. He found that the relationship between relative price variability and the actual level of inflation was generally positive and significant, and was stable after excluding food and energy prices. Both expected and unexpected inflation had a positive and significant relationship with RPV. He also found that relative price variability appeared to respond asymmetrically to changes in inflation, suggesting some degree of price rigidity.

Critics have strongly disagreed with the conclusions of Vining and Elwertowski, Parks, and their successors. Driffil, Mizon, and Ulph (1990) concluded that Vining and Elwertowski "do not provide convincing evidence of a strong positive relationship between relative price variability and inflation," while Bomberger and Makinen (1993) attributed Parks' findings entirely to the oil shocks.

Critics have especially focused on specifications which regressed relative price variability on the absolute value of inflation (or, identically, on inflation during periods when it is strictly positive) or squared inflation. These variables are definitionally related, so that there will be a statistical relation between them no matter what the data generating process, as discussed in Hartman (1991) and Grier and Perry (1993). Hartman argued that due to the statistical relationships between the various measures of inflation, some of the results are spurious. He supported an analysis along the lines of Hercowitz (1981), who used monetary variables as instruments. However, Hartman concluded that using the level of inflation as a single regressor is econometrically valid 
RPV - Page 6

The debate over intra-market RPV parallels the debate over inter-market RPV ${ }^{3}$ A number of authors have found a positive relationship between intra-market price variability and inflation. Domberger (1987) examined the movements of prices of goods within 4-digit SICs in the UK, while Beaulieu and Mattey (1994) looked within commodity groups in the US. Van Hoomissen (1988), Tommasi (1993) and Lach and Tsiddon (1992) used data on the same product across different stores in countries which were experiencing high rates of inflation. ${ }^{4}$ These studies generally reported a positive relationship between inflation and price variability.

In contrast, Reinsdorf (1994), used data from the Volcker deflation in the US to find a negative relationship between price dispersion and unexpected inflation but a positive relationship with expected inflation. ${ }^{5}$

Our approach differs from this existing literature by controlling for nationwide and monetary disturbances, utilizing the cross-sectional information from individual US cities. Therefore neither monetary policy nor OPEC oil shocks can be driving our results.

\section{Data and Approach}

\section{A. Data}

Our data consists of two balanced panels of annual Consumer Price Index inflation rates for US

${ }^{3}$ The data used in this paper can not be used to calculate intra-market figures.

${ }^{4}$ Israel 1971-1984, Argentina 1990, and Israel late 1970s and early 1980s, respectively.

${ }^{5}$ Like Beaulieu and Mattey, Reinsdorf examined the distinct concept of relative price dispersion, defined as the standard deviation of various prices for the same good at a particular point in time, but across different locations. 
cities. The first panel runs from 1954-1986 for 19 US cities. ${ }^{6}$ For each city, we used price indices calculated by the US Bureau of Labor Statistics (BLS) for the total annual average consumer price level and for 14 categories of goods and services. ${ }^{7}$ The second panel runs from 1977 to 1986 and includes five additional cities, four more categories of goods, and provides a set of price indices which exclude particular classes of commodities from the total consumer price index. ${ }^{8}$

We chose these two panels to provide long and wide cross-sections of cities with the greatest possible level of disaggregation. The disaggregated components provide almost complete coverage of the total components of the CPI: in June 1983, the components of the 1954-86 sample represent about 78 per cent of the CPI and the components of the 1977-86 sample represent 92 per cent of the CPI. In terms of cities, the coverage is less complete: the 26 cities in the 1977-86 sample represent about half the weight of the CPI. We truncate the sample in 1986 because the BLS changed its methodology after 1986, substantially decreasing the sample size and frequency of observation that underlie the city price indices. After 1986, the city-level components of the CPI became much more volatile, due to increased measurement error.

${ }^{6}$ More precisely, the geographical unit is the (consolidated) metropolitan statistical area, or (C)MSA. They are: Atlanta, Baltimore, Boston, Buffalo, Chicago, Cincinnati, Cleveland, Detroit, Houston, Kansas City, Los Angeles, Milwaukee, Minneapolis-St Paul, New York, Pittsburgh, St. Louis, San Francisco, Seattle, and Washington DC.

${ }^{7}$ Cereal and bakery products; meats, poultry and fish; dairy products; fruit and vegetables; food away from home; shelter; household fuels and utilities; men's apparel; women's apparel; footwear; private transportation; public transportation; medical care; and personal care.

${ }^{8}$ The five cities are Anchorage, Dallas, Denver, Honolulu and San Diego. The four additional categories are alcoholic beverages, other food at home, entertainment, and household furnishings. This panel also replaces personal care with the more inclusive "other goods and services". 
It is important to note that US inflation was almost always positive during this period, as shown in Figure 1. This means that descriptions of the pricing process which rely on positive trend inflation (such as Ball and Mankiw (1994)) are relevant during this period.

Using our indexes, we followed standard practice in defining inflation for city $\mathrm{j}$ as

$$
\pi_{j t}=\ln P_{j, t}-\ln P_{j, t-1}
$$

where $P_{j t}$ is the price index for city $j$ in year $t$. Relative price variability for city $j$ at time $t$ was defined as

$$
\sigma_{j t}=\sqrt{\sum_{i=1}^{n} \frac{1}{n-1}\left(\pi_{i j t}-\left[\sum_{i=1}^{n} \frac{1}{n} \pi_{i j t}\right]\right)^{2}}
$$

where $i$ indexes commodities. ${ }^{9}$

From these city-level variables, we subtracted the US national inflation rate and RPV (shown in Figure 1), creating:

$$
\begin{aligned}
& \hat{\pi}_{j \mathrm{t}}=\pi_{\mathrm{jt}}-\pi_{\mathrm{USt}} \\
& \hat{\sigma}_{\mathrm{jt}}=\sigma_{\mathrm{jt}}-\sigma_{\mathrm{USt}}
\end{aligned}
$$

so that the variables are expressed as deviations from national averages. We also calculated $\left|\hat{\pi}_{\mathrm{j} t}\right|$, the absolute value of $\hat{\pi}_{\mathrm{jt}}$.

We focus on deviations from national averages because we want to examine evidence which is not driven by monetary policy or other national events. In our regressions, we will use fixed

${ }^{9} \pi_{\mathrm{ijt}}$ and the underlying $\mathrm{P}_{\mathrm{ijt}}$ indices are also used to calculate $\pi_{\mathrm{jt}}$ and $\mathrm{P}_{\mathrm{jt}}$, so that $\mathrm{P}_{\mathrm{jt}}$ is a weighted average of the $P_{i j \mathrm{i}}$. In practice we observe most but not all of the individual price indices and inflation rates $P_{\mathrm{ijt}}$ and $\pi_{\mathrm{jit}}$ that the BLS uses to calculate the total CPI price index $\mathrm{P}_{\mathrm{jt}}$ and $\pi_{\mathrm{jt}}$. $\pi_{\mathrm{jt}}$ is thus an almost exact linear combination of the $\pi_{\mathrm{ijt}}$ 's. 
effects to control for city-specific and year-specific components of city inflation. The fixed city effects allow cities to have different average inflation and RPV over the sample period, and the fixed year effects control for different average levels of RPV and inflation in different years.

Table 1 shows summary statistics for the city data, 1954-1986. Figure 2 plots $\hat{\pi}_{\mathrm{jt}}$ (the difference between the city inflation rate and the national rate) on the horizontal axis, and $\hat{\sigma}_{\mathrm{jt}}$ (the difference between the standard deviation (across sub-groups of commodities) in the city and the standard deviation in the nation) on the vertical axis, after controlling for city and year effects. ${ }^{10}$ Another way of describing the horizontal axis is that it shows the change in the relative price of a basket of goods in a given city compared to the national average.

\section{B. Empirical Strategy}

In testing for a positive correlation between inflation and RPV, our basic strategy is to test for a positive slope in Figure 2. We are interested in the relationship between $\hat{\sigma}_{\mathrm{jt}}$ and $\hat{\pi}_{\mathrm{jt}}{ }^{11}$ Other researchers, for example Tommasi (1993), focus on the relationship between RPV and the absolute value of inflation, which corresponds to looking for a V-shape in Figure $2 .{ }^{12} \mathrm{We}$ are hesitant to try to draw inferences (using our data) about the relationship between the absolute value of inflation and RPV. Although we include $\left|\hat{\pi}_{\mathrm{jt}}\right|$, the absolute value of $\hat{\pi}_{\mathrm{jt}}$, as a control variable in the regressions, we believe city data are likely to cause this variable to be correlated

${ }^{10}$ That is, we plot the residuals from a regression of $\hat{\pi}_{\mathrm{jt}}$ and $\hat{\sigma}_{\mathrm{jt}}$ on a set of dummy variables (one for each city and each year.) The fact that we use year dummies on the right hand side means that it is irrelevant whether we subtract the national average from the left-hand side. Calculating the deviation from the national average is only relevant when computing the variable $\left|\hat{\pi}_{\mathrm{jt}}\right|$.

${ }^{11}$ We regress $\hat{\sigma}_{\mathrm{jt}}$ on $\hat{\pi}_{\mathrm{jt}}$ to show the contemporaneous correlation between these two variables. The reverse regression is shown in Table 6 .

${ }^{12}$ Tommasi (1993) finds rather dramatic V-shapes in his Argentine data. 
with RPV.

First, the data might conform to a V-shaped pattern in Figure 2 (i.e. $\left|\hat{\pi}_{\mathrm{jl}}\right|$ and $\hat{\mathrm{o}}_{\mathrm{jt}}$ might be positively correlated) due to the definition of the different variables, as in Hartman (1991). Both $\left|\hat{\pi}_{\mathrm{j} t}\right|$ and $\hat{\sigma}_{\mathrm{jt}}$ are functions of the realizations of $\pi_{\mathrm{ijt}}$. Suppose that we examined a set of means and standard deviations from a series of sets of random numbers with the same mean. Then, depending on the data generating process, conditional on having an above- or below-average realized mean in a given set, we might also find a high realized standard deviation in the same set. ${ }^{13}$ Even if all cities in the US had identical relative and aggregate prices, but the different prices were reported with city-level error, we might expect to see $\left|\hat{\pi}_{\mathrm{jt}}\right|$ explain $\hat{\sigma}_{\mathrm{jt}}$

The second reason to expect a V-shaped pattern is based on economic theory and depends on the relative shocks and related adjustment processes of cities in the US. Consider the following basic story, in which prices are fully flexible and set in competitive markets with full information. Different cities face different relative shocks in different years. This shock could be a change in the demand for that cities' production, or a change in the relative (national) price of goods that city disproportionately consumes. Some goods are highly tradeable and intercity arbitrage forces their prices to be (roughly) equal across cities. Other goods (e.g. houses) are highly non-tradeable and their prices are different across cities. When a city receives, say, a negative demand shock compared to the national average, two things happen: (a) the relative price of all goods in that city falls, so that the city's inflation rate is less than the national average and (b) the relative prices of different goods within that city change as well. The first effect, (a),

${ }^{13}$ For example, it is easy to generate a V-shaped pattern using iid mean-zero normal distributions. With 14 categories, for example, one would observe a clear V-shaped pattern by having $\pi_{\mathrm{ij}} \sim \mathrm{N}(0,1)$ for $\mathrm{J} \leq 13$ and $\pi_{\mathrm{ij}} \sim \mathrm{N}(0,10)$ for $\mathrm{j}=14$. 
RPV - Page 11

is essentially identical to the familiar real depreciation with fixed exchange rates. The second effect, (b), occurs since the prices of traded goods are constrained to be equal across cities, but non-traded goods prices must adjust fully to the shock, so that the price changes of traded and non-traded goods become more dispersed following a shock. Thus we expect to see higher RPV in cities that have total inflation that is either higher or lower than the national average.

Since it is difficult to know whether measurement errors or other factors might be causing a V-shaped curve to appear in the data, in our empirical tests, we therefore focus on the monotonic relationship between city inflation and city RPV (or, equivalently, on asymmetries in the V-shape). We ask: given $\left|\hat{\pi}_{\mathrm{jt}}\right|$, is $\hat{\pi}_{\mathrm{jt}}$ positively correlated with $\hat{\sigma}_{\mathrm{jt}}$ ? That is, we ask whether, holding constant the absolute value of a city's inflation rate relative to the national average, higher inflation is associated with higher RPV

\section{Regression Results}

\section{A. Baseline Results}

We stacked our 627 city-year observations and ran fixed-effects regressions, including a dummy variable for each city and year. The first column in Table 2 reports the coefficients from our baseline results in the $1954-86$ sample. The coefficient of interest, on $\hat{\pi}_{\mathrm{jt}}$, is positive $(0.21)$ and highly significant (with a t-statistic of about 4). The coefficient on $\left|\hat{\pi}_{\mathrm{jt}}\right|$ is also positive but insignificant. In words, column (1) says that holding constant the absolute value of city inflation relative to the national average, higher inflation is associated with higher RPV. By estimating separate coefficients for $\left|\hat{\pi}_{\mathrm{jt}}\right|$ and $\hat{\pi}_{\mathrm{jt}}$, we are essentially estimating the slope of two different lines on either side of the vertical axis in Figure 2, with the left hand side having a slope equal to the difference between the $\left|\hat{\pi}_{\mathrm{jt}}\right|$ and $\hat{\pi}_{\mathrm{jt}}$ coefficients, and the right hand side having a slope equal to the 
sum. The line in Figure 2 shows the slopes implied by the regression. ${ }^{14}$

In the rest of this section, we describe a battery of cross-sectional regressions testing whether this positive and significant coefficient on $\hat{\pi}_{\mathrm{jt}}$ is robust. We found that the relationship is strikingly robust to a variety of different assumptions, and is not caused by a particular observation, city, year, time-horizon, or category of goods and services. This contrasts with the aggregate evidence on inflation and RPV in the postwar US time series, the robustness of which is a matter of dispute.

We first checked to see our conclusions were affected by different assumptions about the nature of the disturbance term. Table 2 also shows White (1980) standard errors to allow for unknown forms of heteroskedasticity. This correction made little difference to the calculated standard errors. The next column shows the standard errors calculated as in Newey-West (1987), to allow for residuals that are both autocorrelated and heteroskedastic. ${ }^{15}$ Last, we also report standard error estimates that abstract from serial correlation but permit general patterns of crosssectional dependence. We dropped the year dummies from the regression and instead estimated OLS coefficients and an error covariance matrix which allowed the error term to be correlated for each pair of cities and to have city-specific heteroskedasticity ${ }^{16}$ The last two columns in Table 2

${ }^{14}$ The line in Figure 2 shows the implied slopes, but it does not show the fitted values from the regression since those involve the interaction between all the right-hand-side variables, including the dummies for city and year.

${ }^{15}$ The first-order autocorrelation coefficient for the residual was 0.04 and insignificantly different from zero. We calculated the Newey-West errors using a window of two lags.

${ }^{16}$ We estimated the covariance matrix, allowing for cross-sectional correlation and groupwise heteroskedasticity as in equation 16-7 of Greene (1990). We estimated the covariance terms using T-K in the denominator of Greene's equation $16-8$, as this produced more conservative (bigger) standard errors in the last column of Table 2. 
report the coefficients and standard errors from this regression; again the results are about the same.

Table 3 continues the sensitivity analysis. We first checked to see whether using different control variables affected the coefficient on $\hat{\pi}_{\mathrm{jl}}$. Using both the squared value of the inflation deviation, $\hat{\pi}_{\mathrm{j}}{ }^{2}$, as well as $\left|\hat{\pi}_{\mathrm{jt}}\right|$, (so that the equation fitted both a quadratic and piecewise linear) did not materially change the coefficient on $\hat{\pi}_{\mathrm{jt}}$ in column (1). The results were also robust to the inclusion of a lagged dependent variable (shown in column (2)) ${ }^{17}$ Column (3) shows that the coefficient on inflation changes only slightly when no other regressors accompany $\hat{\pi}_{\mathrm{jt}}$.

Although we could reject the hypothesis that the city and year dummies were not jointly significant, we also tried excluding these dummies from the right-hand side. These restrictions had almost no effect on the coefficient on $\hat{\pi}_{\mathrm{jt}}$ as shown in column (4) of Table 3 .

Figure 2 suggests that outliers may be influencing the regression results. ${ }^{18}$ We therefore discarded the top and bottom 1 percent of the sample ranked on the values of $\hat{\pi}_{j \mathrm{t}}$ and $\hat{\sigma}_{\mathrm{jt}}$ shown in Figure 2, and reran the regression. ${ }^{19}$ Column (5) shows the result: discarding outliers raises the coefficient on $\hat{\pi}_{\mathrm{jt}}$, although the coefficient is not significantly different from the full sample

${ }^{17}$ We also tried adding the lags of the regressors, $\left|\hat{\pi}_{\mathrm{j}-1}\right|$ and $\hat{\pi}_{\mathrm{j}-1-1}$, to the right-hand-side; these were also insignificant and had no impact on the magnitude and significance of $\hat{\pi}_{\mathrm{j} t}$.

18 The prominent outlier in the graph with a standard deviation of above .10 is the observation for Atlanta in 1972; in that year, the price index for public transportation fell by more that 50 percent.

19 That is, we discarded observations based on extreme values of $\hat{\pi}_{\mathrm{jt}}$ and $\hat{\sigma}_{\mathrm{jt}}$ after controlling for time and city as in Figure 2. As an alternative procedure for dealing with outliers, we also estimated the baseline regression using Least Absolute Deviations techniques. This procedure resulted in a coefficient of 0.175 on $\hat{\pi}_{\mathrm{jt}}$ and 0.142 on $\left|\hat{\pi}_{\mathrm{jt}}\right|$, with standard errors of 0.026 and 0.057 respectively. 
estimate (the coefficient on $\left|\hat{\pi}_{\mathrm{jt}}\right|$ falls, however, as might be expected if it were a statistical artifact generated by measurement error). ${ }^{20}$

We investigated the subsample stability of the estimates by splitting the sample roughly in half. Since the Nixon price controls were initiated in 1971, we used the two samples 1954-1970 and 1971-1986. Columns (6) and (7) in Table 3 shows that both the coefficients on $\hat{\pi}_{\mathrm{jt}}$ were positive and significant, and were statistically indistinguishable from each other ${ }^{21}$ The stability of the coefficient on $\hat{\pi}_{\mathrm{jt}}$ is remarkable, given the radically different environment of aggregate inflation and oil shocks in the two periods.

We also tried estimating separate year-by-year equations, so that for each of the 33 years 1954-86, we ran a simple regression on 19 city observations, including $\hat{\pi}_{\mathrm{jt}}, \hat{\pi}_{\mathrm{jt}} \mid$, and a constant on the right hand side (using White standard errors). Of these 33 regressions (which are not reported here), 23 had a positive estimated coefficient on $\hat{\pi}_{\mathrm{jt}}{ }^{22}$ Seven of the 23 positive coefficients were statistically significant (namely 1955, 1969, 1970, 1977, 1978, 1980 and 1985), while none of the 10 negative coefficients were.

We next investigated whether the results are driven primarily by the non-traded goods in the sample. We might expect traded goods inflation to be more similar across cities while non-traded goods inflation may have a significant local component. Hence we divided the 14 commodities

${ }^{20} \mathrm{We}$ also tested whether a specific city was driving the results. We re-estimated the baseline regression 19 times, each time omitting a specific city. This procedure had little impact on the coefficient on $\hat{\pi}_{\mathrm{j} t}$, which ranged between 0.19 and 0.24 and was always highly significant.

${ }^{21}$ The latter period includes the 1972 outlier mentioned previously.

${ }^{22}$ If the coefficients of $\hat{\pi}_{\mathrm{jt}}$ were drawn from an IID distribution with 0.5 probability of being positive, the probability of having 10 or fewer negative observations would be 1.75 percent (the probability of 10 or fewer of either sign would be 3.51 percent). 
into the two types and recalculated $\hat{\mathrm{o}}_{\mathrm{jt}}$ and $\hat{\pi}_{\mathrm{jt}}$ using only the traded or non-traded goods. ${ }^{23}$ The results are shown in Table 4. The coefficient on $\hat{\pi}_{\mathrm{jt}}$ in the traded goods regression is lower than that for the non-traded goods, but both estimates are significantly different from zero and are not significantly different from each other. Correspondingly, we also dropped each of the 14 commodities in turn from the calculation of $\hat{\sigma}_{j t}$. There was no discernible difference in the results (which are not reported here).

We re-estimated the baseline regression using the 1977-86 panel. These results, in Table 4, are similar to the 1954-86 baseline, with the coefficient on $\hat{\pi}_{j t}$ a bit lower. In addition to providing a larger number of cities, the 1977-86 sample also provides a set of indices calculated by the BLS which show the effect of specific components of the CPI on the total index ${ }^{24}$ The last column of Table 4 shows the effect of excluding the quintessential non-traded good, housing, from the calculation of both $\hat{\pi}_{\mathrm{jt}}$ and $\hat{\sigma}_{\mathrm{jt}}{ }^{25}$ The coefficient of $\hat{\pi}_{\mathrm{jt}}$ is higher than in the baseline 1977-86 case, showing that the results are not driven by fluctuations in regional real estate markets.

\section{B. Longer Time Horizons}

To investigate whether the correlation between inflation and RPV was a short or long term phenomenon, we used our data to examine inflation rates and relative price changes over longer

${ }^{23}$ After reviewing the contents of each category, we judgementally classified food away from home, shelter, public transportation, medical care and personal care as non-traded goods.

${ }^{24}$ These indices could in principle be calculated for the entire 1954-86 sample. However, because the BLS uses different (unpublished) weights for each city and year when calculating the overall CPI, we were not able to accurately reproduce these series with available information.

${ }^{25}$ We used the index of total inflation less shelter where shelter includes rent, homeowners equivalent rent, house maintenance and repair and lodging while out of town. This is the only place in this paper where we do not use total CPI inflation in calculating $\hat{\pi}_{\mathrm{jt}}$ and $\left|\hat{\pi}_{\mathrm{jt}}\right|$. 
horizons. Our expectation, based on menu-cost or misperceptions models, was that the relationship would be short-lived. We were surprised to find that the correlation persisted for intervals of up to five or ten years. Since other evidence indicates most prices are changed within a given five or ten year period, this finding casts some doubt on models (such as menu costs) in which infrequent price adjustment leads to RPV in response to real or nominal shocks. ${ }^{26}$

We recomputed $\hat{\pi}_{\mathrm{jt}}$ and $\hat{\mathrm{o}}_{\mathrm{jt}}$ using price changes over 5 year intervals, and re-estimated the baseline regression in two ways: using overlapping and non-overlapping observations. ${ }^{27} \mathrm{We}$ estimated the baseline regression using a dummy variable for each city and time period. Table 5 shows the regression results. For the overlapping observations, the OLS residuals are naturally highly positively autocorrelated. ${ }^{28}$ For both the overlapping and non-overlapping observations, we corrected the standard errors on the coefficients for autocorrelation of the residuals (as well as for possible heteroskedasticity) as in Hansen (1982) and Hansen and Hodrick (1980). ${ }^{29}$

At a five year horizon, the regressions using both the overlapping and non-overlapping data

${ }^{26}$ Kashyap (1995) finds that in 1953-1987, catalog retailers change their prices on average once every 14.7 months; Cecchetti (1986) finds a lower frequency of three to seven years, for magazine price changes in the 1953-1979 period.

${ }^{27}$ So, for the non-overlapping observations, the five year inflation rates were calculated for the periods 1956-1961, 1961-1966, 1966-1971, 1971-1976, 1976-1981 and 1981-1986 for each city and category.

${ }^{28}$ For the overlapping observations, the first-order autocorrelation coefficient is 0.71 for the 5 -year horizon and 0.83 for the 10 -year horizon. For the non-overlapping observations, the coefficients are -0.18 and -0.28 , respectively.

${ }^{29}$ We assumed that the residual in these regressions had a moving average term of order 4 for the 5-year horizon, and of order 9 for the 10-year horizon. Using Newey-West (1987) instead of Hansen-Hodrick (1980) and Hansen (1982), so that the autocovariance terms are downweighted, produces standard errors which are extremely similar. 
show a positive and significant coefficient on $\hat{\pi}_{\mathrm{jt}}$. At a ten year horizon, both sets of regressions still yield a positive and fairly sizable correlation between inflation and RPV. Not surprisingly, using the largest possible interval of 34 years shows no relationship whatsoever.

\section{Skewness}

Ball and Mankiw (1995) argue that the skewness of relative shocks is an important determinant of inflation, and that empirically, "the inflation-skewness relationship is in fact stronger than the inflation-variance relationship." We investigated this relationship at the city level by calculating city level inflation skewness:

$$
k_{j t}=\frac{\sum_{i=1}^{n} \frac{1}{n}\left(\pi_{i j t}-\left[\sum_{i=1}^{n} \frac{1}{n} \pi_{i j t}\right]\right)^{3}}{\left.\left(\sqrt{\frac{n}{n-1}}\right) \sigma_{j t}\right)^{3}}
$$

and the deviation from national skewness, $\hat{\mathrm{j}}_{\mathrm{jt}}=\mathrm{k}_{\mathrm{ijt}}-\mathrm{k}_{\mathrm{USt}}$.

Ball and Mankiw (1995) analyze the time series relation between $\mathrm{k}_{\mathrm{USv}} \pi_{\mathrm{USv}}$ and $\sigma_{\mathrm{USt}}$, while we look at the analogous city deviations, $\hat{k}_{\mathrm{jt}}, \hat{\pi}_{\mathrm{jt}}$ and $\hat{\sigma}_{\mathrm{jt}-\mathrm{I}}$ In the tables thus far, we have regressed the standard deviation on inflation, to make our results comparable with previous research. Ball and Mankiw (1995) instead regress the level of inflation on measures of its standard deviation and skewness; we attempted to reproduce Ball and Mankiw's analysis using our data ${ }^{30}$

Table 6 reproduces Ball and Mankiw's Table III, using city deviations from national inflation, standard deviations of inflation rates, and skewness coefficients. An important caveat is that

${ }^{30}$ De Abreu Lourenco and Gruen (1995) reproduce the Ball and Mankiw analysis using Australian data and find that the effect of RPV is greater at lower inflation rates, while the effect of skewness is greater at higher inflation rates. 
while Ball and Mankiw used inflation rates for more than 200 different commodities (using the Producer Price Index), we had only 14 categories of goods and services in our 1954-1986 data set.

First, note that the reverse regression of inflation on RPV in the column (1) gives results similar to those presented previously: inflation and RPV are positively correlated at the city level. ${ }^{31}$

Given our crude level of disaggregation, we find the results in columns (2) through (5) to be fairly supportive of Ball and Mankiw (1995). Almost all of the signs of the coefficients in Table 6 match with those of Ball and Mankiw. ${ }^{32}$ Overall, the chief difference between Table 6 and Table III of Ball and Mankiw (1995) is that we find $\hat{\sigma}_{\mathrm{jt}}$ to be robustly significant and to have more explanatory power than $\mathrm{k}_{\mathrm{jt}}$, which is more fragile; they find the opposite result. ${ }^{33}$ As before, we briefly checked the sensitivity of the skewness results with respect to outliers, and again found $\hat{\sigma}_{\mathrm{jt}}$ robustly significant and positive, but terms involving $\hat{\mathrm{j}}_{\mathrm{jt}}$ more fragile.

In summary, although we find some evidence that skewness matters at the city level, we conclude that the strong positive correlation between RPV and inflation is not chiefly a function of the statistical relationship between skewness and inflation.

${ }^{31}$ Like aggregate inflation (but unlike $\hat{o}_{\mathrm{jt}}$ ), inflation at the city level is positively autocorrelated; cities with above-average inflation this year are likely to have above-average inflation next year.

${ }^{32}$ Only one of the coefficients in Table 6 has a different sign than its counterpart in Ball and Mankiw (1995) Tables IIIA and Table IIIB. They find $k_{\mathrm{USt}}$ to be negative in (4).

${ }^{33}$ Specifically, they find that $\sigma_{U S t}$ is always insignificant in their Table IIIA, and that $\mathrm{k}_{\mathrm{USt}}$ and $\mathrm{k}_{\mathrm{USt}} * \sigma_{\mathrm{USt}}$ are always significant or marginally significant. 
RPV - Page 19

\section{Extensions}

The analysis in this paper, like most of the previous work, has estimated a simple reduced form. An important extension is to move to structural estimation. City data has, in addition to the virtues already mentioned, the added benefit that a variety of useful instruments exist to measure exogenous shocks to demand. For example, one could proxy for changes in exogenous demand by using aggregate movements in sectoral production in combination with the industrial composition of a city's manufacturing base. Other traditional instruments, such as military spending, are available at the state level (see Davis, Loungani, and Mahidhara (1995) for an extensive list). For some cities, manufacturing wages are also available annually, so that wage-price dynamics could be studied. Blanchard and Katz (1992) report some of the basic facts about employment at the regional level within the US.

Another extension would be to decompose city inflation into expected and unexpected components. Econometrically, this seems straightforward, since $\hat{\pi}_{\mathrm{jt}}$ is autocorrelated (as shown in Table 6). However, since the data on city inflation used in this paper is rarely used by economists or mentioned in the press, it is not immediately clear whether residents of US cities even know what $\hat{\pi}_{\mathrm{jt}}$ is, much less form expectations about it

We have studied inter-market RPV in this paper; studying intra-market RPV in US cities would also be useful. Although Reinsdorf (1994) reports on nine US cities for the three year period 1980-1982, it might be possible to get a larger cross section of cities for these years and test whether cities with above average inflation also have above average intra-market RPV.

\section{Conclusion}

The main innovation of this paper is the use of cross-sectional data on inflation and relative price 
variability. In using differences across city, we automatically exclude as explanations those theories of the inflation/RPV nexus that rely on monetary policy, since different cities do not have different monetary policy. Although on the national level and in the long run, inflation may be always and everywhere a monetary phenomenon, by construction our approach only captures price changes which are caused by relative shocks to cities. ${ }^{34}$

Although cross-sectional data has advantages over time-series data in this respect, it also has disadvantages in that the evidence presented here does not necessarily directly relate to national inflation and RPV. That is, national inflation and city-specific inflation are by construction orthogonal variables, so we cannot aggregate city-specific inflation and RPV shocks to reach conclusions about the national variables. Another limitation is that, as with many studies in this field, we are simply observing the contemporaneous correlation of two endogenous variables and so cannot come to strong conclusions about causality. Our approach is useful, however, in that it illuminates basic facts about the price system that are applicable to the national level. We have found a robust empirical regularity: across cities, RPV and inflation (relative to the national average) are strongly correlated. This correlation cannot be explained by theories that depend on monetary or federal government action. In addition, we found that the correlation between inflation and relative price variability was surprisingly persistent over time.

${ }^{34}$ While it is certainly true that monetary and fiscal policy, oil shocks, and other aggregate events may have different regional effects, our evidence is by construction orthogonal to the aggregate events; only the city-specific components of these shocks is examined. 


\section{References}

Ball, Laurence and N. Gregory Mankiw. "Asymmetric Price Adjustment and Economic Fluctuations." Econ. J. 104 (March 1994): 247-261.

Ball, Laurence and N. Gregory Mankiw. "Relative-Price Changes as Aggregate Supply Shocks." Q.J.E. 110 (February 1995):161-194.

Barro, Robert. "Rational Expectations and the Role of Monetary Policy." J. Monetary Economics 2 (January 1976): 1-32.

Beaulieu, J. Joseph, and Joe Mattey. "The Effects of General Inflation and Idiosyncratic Costs Shocks on Within-Commodity Price Dispersion: Evidence from Microdata." Working Paper no. 94-12. Finance and Economics Discussion Series, Federal Reserve Board 1994.

Benabou, Roland. "Search, Price Setting, and Inflation." Review of Economic Studies 55 (July 1988): 353-373.

Blanchard, Oliver and Lawrence F. Katz. "Regional Evolutions." Brookings Papers Econ. Activity no 1 (1992):1-61.

Bomberger, William A. and Gail E. Makinen. "Inflation and Relative Price Variability: Park's Study Reexamined." J. Money, Credit, and Banking 25 (November 1993):854-861.

Cecchetti, Stephen G. "The Frequency of Price Adjustment: A Study of the Newsstand Prices of Magazines, 1953-1979.” J. of Econometrics 20 (August 1986): 255-74.

Davis, Steven, Prakash Loungani, and Ramamohan Mahidhara. "Regional Unemployment Cycles." Paper presented at the February 1995 NBER Economic Fluctuations Conference.

De Abreu Lourenco, Richard and David Gruen, "Price Stickiness and Inflation." Reserve Bank of Australia, Research Discussion Paper \#9502.

Domberger, Stephen. "Relative Price Variability and Inflation: A Disaggregated Analysis." J.P.E. 95 (June 1987):547-566

Driffil, John, Grayham Mizon, and Alistair Ulph. "Costs of Inflation." In The Handbook of Monetary Economics Volume 2, edited by Benjamin Friedman and Frank Hahn. Amsterdam: North Holland, 1990.

Fischer, Stanley. "Relative Shocks, Relative Price Variability, and Inflation." Brookings Papers Econ. Activity no. 2 (1981):381-431. 
Fischer, Stanley. "Relative Price Variability and Inflation in the United States and Germany.” European Economic Review 18 (May/June 1982):171-196.

Glejser, Herbert. "Inflation, Productivity, and Relative Prices - A Statistical Study." Review of Economics and Statistics 47 (February 1965):76-80.

Graham, Frank D. Exchange, Prices and Production in Hyper-Inflation: Germany, 1920-23. Princeton, N.J.: Princeton University Press, 1930.

Greene, William H. Econometric Analysis. Englewood Cliffs, N.J.: Prentice-Hall, 1990

Grier, Kevin B. and Mark J. Perry. "Inflation, Inflation Uncertainty and Relative Price Dispersion: Evidence from Bivariate GARCH-M Models." George Mason University working paper. 1993.

Hansen, Lars Peter. "Large Sample Properties of Generalized Method of Moments Estimators." Econometrica 50 (July 1982): 1029-1054.

Hansen, Lars Peter and Robert J. Hodrick. "Forward Exchange Rates as Optimal Predictors of Future Spot Rates: An Econometric Analysis." J.P.E. 88 (October 1980):829-853.

Hartman, Richard. "Relative Price Variability and Inflation." J. Money Credit and Banking 23 (May 1991):185-205.

Hercowitz, Zvi. "Money and the Dispersion of Relative Prices." J.P.E. 89 (April 1981):328-356.

Kashyap, Anil K "Sticky Prices: New Evidence from Retail Catalogs." Q.J.E. 110 (February 1995):161-194.

Lach, Saul and Daniel Tsiddon. "The Behavior of Prices and Inflation: An Empirical Analysis of Disaggregated Price Data." J.P.E. 100 (April 1992):349-389.

Lucas, Robert. "Some International Evidence on Output-Inflation Tradeoffs." A.E.R. 66 (June 1973):326-334.

Mills, Frederick C. The Behaviour of Prices. New York: National Bureau of Economic Research, 1927.

Newey, Whitney and Kenneth West. "A Simple Positive-Definite, Heteroskedasticity and Autocorrelation Consistent Covariance Matrix." Econometrica 55 (May 1987):703-708.

Parks, Richard. "Inflation and Relative Price Variability." J.P.E. 86 (February 1978):79-95. 
Parsley, David C. "Inflation and Relative Price Variability in the Short and Long Run: New Evidence from US Cities." Vanderbilt University working paper.

Reinsdorf, Marshall. "New Evidence on the Relation between Inflation and Price Dispersion." A.E.R. 84 (June 1994):720-731.

Sheshinski, Eytan and Yoram Weiss. "Inflation and the Costs of Price Adjustment." Review of Economic Studies 64 (June 1977):287-303.

Tommasi, Mariano. "Inflation and Relative Prices Evidence from Argentina." In Optimal Pricing, Inflation, and the Cost of Price Adjustment edited by Eytan Sheshinski and Yoram Weiss. Cambridge, Mass. MIT Press ,1993.

Van Hoomissen, Teresa. "Price Dispersion and Inflation: Evidence from Israel." J.P.E. 96 (December 1988):1303-1314.

Vining, Daniel and Thomas Elwertowski. "The Relationship between Relative Prices and the General Price Level." A.E.R. 66 (September 1976):699-708.

Weiss, Yoram. "Inflation and Price Adjustment: A Survey of Findings From Micro-Data." In Optimal Pricing, Inflation, and the Cost of Price Adjustment, edited by Eytan Sheshinski and Yoram Weiss. Cambridge, Mass. MIT Press, 1993.

White, Halbert "A Heteroskedasticity-Consistent Covariance Matrix Estimator and a Direct Test for Heteroscedasticity.” Econometrica 48 (May 1980):817-838. 


\section{Table 1: Summary Statistics, 1954-1986}

\begin{tabular}{|r|c|c|c|c|c|}
\hline & Mean & Std Dev & Min & Max & N \\
\hline Inflation: $\pi_{\mathrm{Ust}}$ & 0.043 & 0.032 & -0.004 & 0.127 & 33 \\
RPV: $\sigma_{\mathrm{USt}}$ & 0.027 & 0.013 & 0.012 & 0.065 & 33 \\
\hline Inflation: $\pi_{\mathrm{jt}}$ & 0.043 & 0.033 & -0.010 & 0.153 & 627 \\
$\hat{\pi}_{\mathrm{jt}}$ & 0.000 & 0.008 & -0.030 & 0.042 & 627 \\
$\left|\hat{\pi}_{\mathrm{jt}}\right|$ & 0.006 & 0.006 & 0.000 & 0.042 & 627 \\
\hline RPV: $\sigma_{\mathrm{jt}}$ & 0.035 & 0.017 & 0.007 & 0.148 & 627 \\
$\hat{\sigma}_{\mathrm{jt}}$ & 0.007 & 0.011 & -0.014 & 0.126 & 627 \\
\hline Skewness: $\mathrm{k}_{\mathrm{jt}}$ & 0.240 & 0.845 & -3.178 & 2.984 & 627 \\
$\hat{\mathrm{k}}_{\mathrm{jt}}$ & 0.026 & 0.886 & -4.413 & 3.363 & 627 \\
\hline
\end{tabular}

Notes: $\hat{\pi}_{\mathrm{jt}}=\pi_{\mathrm{jt}}-\pi_{\mathrm{Ust}}$ is the city inflation deviation, where $\pi_{\mathrm{jt}}$ is the inflation rate in city $\mathrm{j}$ in year $\mathrm{t}$. $\left|\hat{\pi}_{\mathrm{jt}}\right|$ is the absolute value of the city inflation deviation. $\sigma$ is the standard deviation of inflation rates across categories of goods and services. $\hat{\sigma}_{\mathrm{jt}}=\sigma_{\mathrm{jt}}-\sigma_{\mathrm{USt}}$ for city $\mathrm{j}$ in year $\mathrm{t}$. $\mathrm{k}$ is the skewness coefficient of inflation rates across categories. $\hat{k}_{\mathrm{jt}}=\mathrm{k}_{\mathrm{jt}}-\mathrm{k}_{\mathrm{USt}}$ for city $\mathrm{j}$ in year $\mathrm{t}$. 
Table 2: Baseline Regression Results, 1954-1986

\begin{tabular}{|l|c|c|c|c|c|c|}
\hline & \multicolumn{4}{|c|}{ Baseline Regression Results } & \multicolumn{2}{c|}{ No City Dummies } \\
\hline \multirow{2}{*}{} & Coefficients & \multicolumn{2}{|c|}{ Standard Errors } & Coefficients & S.E.'s \\
\cline { 2 - 7 } & & OLS & White & $\begin{array}{c}\text { Newey- } \\
\text { West }\end{array}$ & & $\begin{array}{c}\text { Cross-City } \\
\text { Correlation }\end{array}$ \\
\hline$\hat{\pi}_{\mathrm{jt}}$ & 0.208 & $(0.052)$ & $(0.046)$ & $(0.044)$ & 0.209 & $(0.037)$ \\
$\left|\hat{\pi}_{\mathrm{j} t}\right|$ & 0.109 & $(0.088)$ & $(0.077)$ & $(0.074)$ & 0.207 & $(0.055)$ \\
\hline$\overline{\mathrm{R}}^{2}$ & 0.07 & \multicolumn{6}{|c}{} & 0.05 & \\
$\mathrm{~N}$ & 627 & \multicolumn{7}{|c|}{} & 627 & \\
\hline
\end{tabular}

Notes: The dependent variable is $\hat{\sigma}_{\mathrm{jt}}=\sigma_{\mathrm{jt}}-\sigma_{\mathrm{USt}}$ for city $\mathrm{j}$ in year $\mathrm{t} . \boldsymbol{\sigma}$ is the standard deviation of inflation rates across categories of goods and services. $\hat{\pi}_{\mathrm{jt}}=\pi_{\mathrm{jt}}-\pi_{\mathrm{USt}}$ is the city inflation deviation, where $\pi_{j t}$ is the inflation rate in city $\mathrm{j}$ in year $\mathrm{t} .\left|\hat{\pi}_{\mathrm{jt}}\right|$ is the absolute value of the city inflation deviation. The first regression includes city and year dummies (coefficients not shown). The second regression includes only year dummies. 
Table 3: Sensitivity Analysis, 1954-1986

\begin{tabular}{|c|c|c|c|c|c|c|c|}
\hline & \multicolumn{3}{|c|}{ Different Regressors } & \multirow{2}{*}{$\begin{array}{c}\text { No } \\
\text { Dummies }\end{array}$} & \multirow{2}{*}{$\begin{array}{c}\begin{array}{c}\text { No } \\
\text { Outliers }\end{array} \\
(5)\end{array}$} & \multirow{2}{*}{$\begin{array}{c}\text { Pre-71 } \\
(6)\end{array}$} & \multirow{2}{*}{$\begin{array}{c}\text { Post-71 } \\
(7)\end{array}$} \\
\hline & (1) & (2) & (3) & & & & \\
\hline$\hat{\pi}_{\mathrm{jt}}$ & $\begin{array}{c}0.201 \\
(0.045)\end{array}$ & $\begin{array}{c}0.198 \\
(0.049)\end{array}$ & $\begin{array}{c}0.218 \\
(0.047)\end{array}$ & $\begin{array}{c}0.203 \\
(0.049)\end{array}$ & $\begin{array}{c}0.251 \\
(0.040)\end{array}$ & $\begin{array}{c}0.289 \\
(0.082)\end{array}$ & $\begin{array}{c}0.163 \\
(0.054)\end{array}$ \\
\hline$\left|\hat{\pi}_{\mathrm{jt}}\right|$ & $\begin{array}{c}-0.017 \\
(0.152)\end{array}$ & $\begin{array}{c}0.132 \\
(0.078)\end{array}$ & & $\begin{array}{c}0.186 \\
(0.068)\end{array}$ & $\begin{array}{c}-0.020 \\
(0.071)\end{array}$ & $\begin{array}{c}-0.054 \\
(0.171)\end{array}$ & $\begin{array}{c}0.183 \\
(0.091)\end{array}$ \\
\hline$\hat{\pi}_{\mathrm{jt}}^{2}$ & $\begin{array}{c}5.471 \\
(5.301)\end{array}$ & & & & & & \\
\hline$\hat{\sigma}_{\mathrm{jt}-1}$ & & $\begin{array}{c}0.032 \\
(0.045)\end{array}$ & & & & & \\
\hline $\mathbf{R}^{2}$ & 0.07 & 0.07 & 0.07 & 0.04 & 0.17 & 0.04 & 0.07 \\
\hline $\mathrm{N}$ & 627 & 608 & 627 & 627 & 599 & 323 & 304 \\
\hline
\end{tabular}

Notes: The dependent variable is $\hat{\sigma}_{\mathrm{jt}}=\sigma_{\mathrm{jt}}-\sigma_{\mathrm{ust}}$ for city $\mathrm{j}$ in year $\mathrm{t} . \sigma$ is the standard deviation of inflation rates across categories of goods and services. $\hat{\pi}_{\mathrm{jt}}=\pi_{\mathrm{jt}}-\pi_{\mathrm{Ust}}$ is the city inflation deviation, where $\pi_{\mathrm{jt}}$ is the inflation rate in city $\mathrm{j}$ in year $\mathrm{t} .\left|\hat{\pi}_{\mathrm{jt}}\right|$ is the absolute value of the city inflation deviation. Standard errors, calculated using White (1980), in parentheses. All regressions include city and year dummies (coefficients not shown) except column (4). 
Table 4: Regression Results: Traded/Non-Traded and 1977-1986

\begin{tabular}{|l|c|c|c|c|}
\hline & \multicolumn{2}{|c|}{$1954-1986$ Sample } & \multicolumn{2}{c|}{$1977-1986$ Sample } \\
\hline & Traded & Non-Traded & Base & $\begin{array}{c}\text { Excluding } \\
\text { Shelter }\end{array}$ \\
\hline$\hat{\pi}_{\mathrm{j} 1}$ & 0.115 & 0.210 & 0.141 & 0.230 \\
& $(0.045)$ & $(0.057)$ & $(0.035)$ & $(0.067)$ \\
$\left|\hat{\pi}_{\mathrm{jt}}\right|$ & 0.019 & 0.286 & 0.090 & 0.239 \\
& $(0.076)$ & $(0.083)$ & $(0.061)$ & $(0.109)$ \\
$\overline{\mathbf{R}}^{2}$ & 0.21 & 0.12 & 0.13 & 0.09 \\
$\mathrm{~N}$ & 627 & 627 & 260 & 260 \\
\hline
\end{tabular}

Notes: The dependent variable is $\hat{\sigma}_{\mathrm{jt}}=\sigma_{\mathrm{jt}}-\sigma_{\mathrm{USt}}$ for city $\mathrm{j}$ in year $\mathrm{t} . \quad \sigma$ is the standard deviation of inflation rates across categories of goods and services. $\hat{\pi}_{\mathrm{jt}}=\pi_{\mathrm{jt}}-\pi_{\mathrm{Ust}}$ is the city inflation deviation, where $\pi_{\mathrm{jt}}$ is the inflation rate in city $\mathrm{j}$ in year $\mathrm{t} .\left|\hat{\pi}_{\mathrm{jt}}\right|$ is the absolute value of the city inflation deviation. Standard errors, calculated using White (1980), in parentheses. All regressions include city and year dummies (coefficients not shown). 
Table 5: Regression Results: Longer Intervals

\begin{tabular}{|l|c|c|c|c|c|}
\hline & \multicolumn{2}{|c|}{ Overlapping } & \multicolumn{2}{c|}{ Non-Overlapping } & \\
\hline & 5 years & 10 years & 5 years & 10 years & 34 years \\
\hline$\hat{\pi}_{\mathrm{jt}}$ & 0.274 & 0.121 & 0.220 & 0.393 & -0.059 \\
& $(0.053)$ & $(0.075)$ & $(0.109)$ & $(0.114)$ & $(0.505)$ \\
$\left|\hat{\pi}_{\mathrm{jt}}\right|$ & 0.042 & 0.115 & 0.269 & 0.200 & -0.316 \\
& $(0.098)$ & $(0.148)$ & $(0.160)$ & $(0.249)$ & $(0.675)$ \\
$\hat{\mathrm{R}}^{2}$ & 0.23 & 0.31 & 0.18 & 0.36 & -0.10 \\
$\mathrm{~N}$ & 551 & 456 & 114 & 57 & 19 \\
\hline
\end{tabular}

Notes: The dependent variable is $\hat{\sigma}_{\mathrm{jt}}=\sigma_{\mathrm{jt}} \boldsymbol{\sigma}_{\mathrm{Ust}}$ for city $\mathrm{j}$ in period $\mathrm{t}$. $\sigma$ is the standard deviation of (n-year) inflation rates across categories of goods and services. $\hat{\pi}_{\mathrm{jt}}=\pi_{\mathrm{jt}}-\pi_{\mathrm{USt}}$ is the city inflation deviation, where $\pi_{\mathrm{jt}}$ is the (n-year) inflation rate in city $\mathrm{j}$ in period $\mathrm{t} .\left|\hat{\pi}_{\mathrm{jt}}\right|$ is the absolute value of the city inflation deviation. Standard errors, calculated using Hansen (1982) with lag window as described in the text, in parentheses. The final column uses standard errors calculated as in White (1980). All regressions include city and year dummies (coefficients not shown), except the final column. 
Table 6: Inflation and the Distribution of Price Changes, 1954-1986

\begin{tabular}{|l|c|c|c|c|c|}
\hline & $(1)$ & $(2)$ & $(3)$ & $(4)$ & $(5)$ \\
\hline$\hat{\pi}_{\mathrm{jt}-1}$ & 0.180 & 0.182 & 0.182 & 0.182 & 0.186 \\
& $(0.060)$ & $(0.061)$ & $(0.059)$ & $(0.061)$ & $(0.059)$ \\
$\hat{\sigma}_{\mathrm{jt}}$ & 0.140 & & 0.139 & & 0.198 \\
& $(0.050)$ & & $(0.044)$ & & $(0.046)$ \\
$\hat{\mathrm{j}}_{\mathrm{jt}}$ & & 0.0009 & 0.0009 & 0.0009 & -0.0003 \\
& & $(0.0004)$ & $(0.0005)$ & $(0.0005)$ & $(0.0006)$ \\
$\hat{\mathrm{K}}_{\mathrm{jt}}{ }^{*} \hat{\sigma}_{\mathrm{jt}-1}$ & & & & 0.002 & 0.050 \\
$\hat{\mathrm{R}}^{2}$ & & & & $(0.008)$ & $(0.015)$ \\
$\mathrm{N}$ & 0.06 & 0.03 & 0.06 & 0.03 & 0.07 \\
& 608 & 608 & 608 & 608 & 608 \\
\hline
\end{tabular}

Notes: The dependent variable is $\hat{\pi}_{\mathrm{jt}}=\pi_{\mathrm{jt}}-\pi_{\mathrm{USt}}$, the city inflation deviation, where $\pi_{\mathrm{jt}}$ is the inflation rate in city $\mathrm{j}$ in year $\mathrm{t} .\left|\hat{\pi}_{\mathrm{jt}}\right|$ is the absolute value of the city inflation deviation. $\sigma$ is the standard deviation of inflation rates across categories of goods and services. $\hat{\sigma}_{\mathrm{jt}}=\sigma_{\mathrm{jt}}-\sigma_{\mathrm{USt}}$ for city $\mathrm{j}$ in year $\mathrm{t}$. $\mathrm{k}$ is the skewness coefficient of inflation rates across categories. $\hat{k}_{\mathrm{jt}}=\mathrm{k}_{\mathrm{jt}}-\mathrm{k}_{\mathrm{USt}}$ for city $\mathrm{j}$ in year $t$. Standard errors, calculated using White (1980), in parentheses. All regressions include city and year dummies (coefficients not shown). 


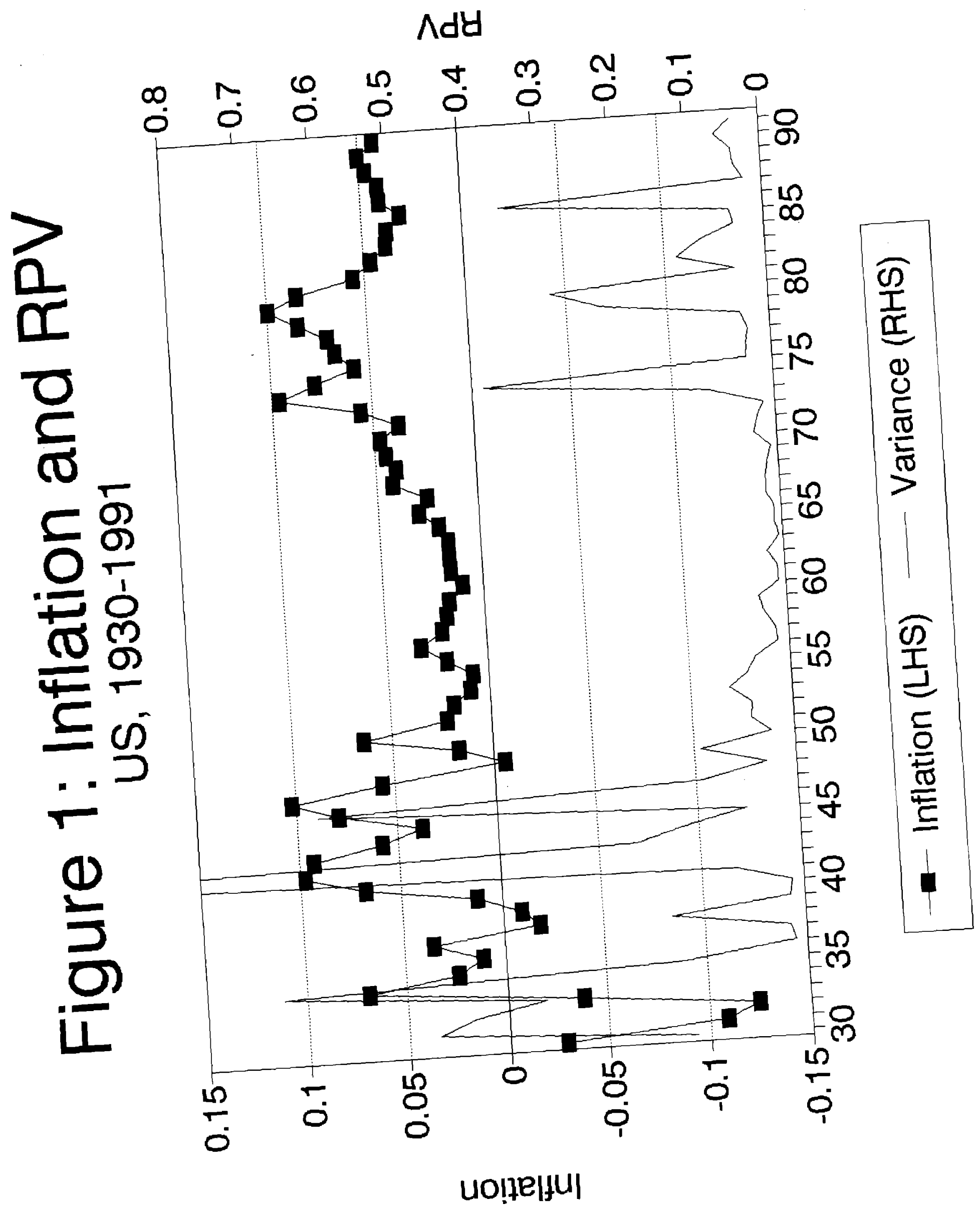




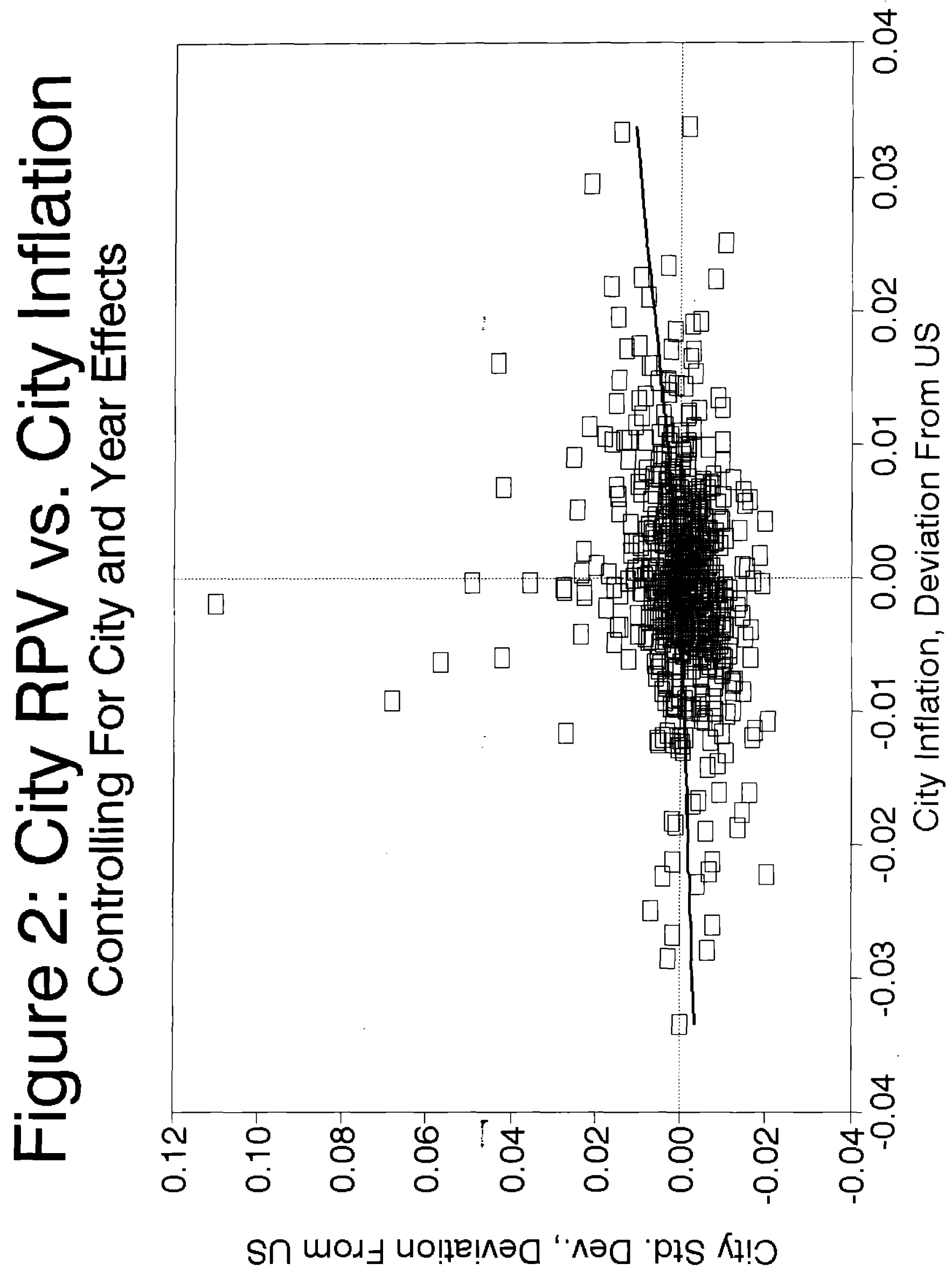

